\title{
Open pond cultures of indigenous algae grown on non-arable land in an arid desert using wastewater
}

\author{
Dominik Winckelmann • Franziska Bleeke • Bimiya Thomas • \\ Clemens Elle • Gerd Klöck
}

Received: 2 March 2015/Accepted: 6 June 2015/Published online: 24 June 2015

(C) The Author(s) 2015. This article is published with open access at Springerlink.com

\begin{abstract}
The algae production on non-arable land in the al-Wusta region of the Sultanate of Oman was evaluated. Pre-cleaned production water (pPW) from the oil production was enriched with nutrients and used as growth medium. The indigenous isolate Scenedesmus sp. MKB was grown in open ponds under semicontinuous conditions. A productivity of $16.1 \mathrm{~g} / \mathrm{m}^{2} /$ day in 2013 and $15.4 \mathrm{~g} / \mathrm{m}^{2} /$ day in 2014 was reached during four different experiments during March and April of 2013 and 2014. Thereby, no influences of light intensity (maximum daily values in between 2400 and $3050 \mu \mathrm{mol}$ photons $/ \mathrm{m}^{2} / \mathrm{s}$ ) or temperature (maximum daily temperatures were between 29.9 and $41.9{ }^{\circ} \mathrm{C}$ ) on productivity were observed (correlation coefficient below \pm 0.5 ). Weed algae, mainly Cyanobacteria and diatoms were detected microscopically in all cultures by the first to seventh day of growth. The increase in weed algae had a negative influence on the maximum photosynthetic efficiency $(Y) . Y$ decreased after a weed algae concentration of ca. $2 \%$ (cell/cell) was reached.
\end{abstract}

Keywords Scenedesmus $\cdot$ Open pond $\cdot$ Arid environment $\cdot$ Produced water $\cdot$ Weed algae $\cdot$ PAM

\section{Introduction}

The possible use of non-arable land (Wagener 1983) would increase the overall land area available for biomass production. A high annual temperature regime, low cloud coverage, and a maximum light exposure, which are typical for semi-arid regions, together with an already existing infrastructure are said to be favorable factors to increase the probability of economical viable microalgal production processes (Grobbelaar 2009). Algae capable of growing in brackish and non-potable water can be used as production strain, and such a choice would result in a reduced water footprint and therefore might result in an increase in potable or agriculturally usable water (Guieysse et al. 2013). However, the use of brackish water might lead to an increase in salt concentration due to evaporation which may cause possible salt stress (Winckelmann et al. 2014).

One of the major issues with the growth of microalgae is the possibility of a sudden and inevitable culture collapse (Hamilton et al. 2014), which can be caused by different means beginning with grazers (Becker 1994; Tillmann 2004), contaminations and pathogens (Gachon et al. 2010), and climatological factors (Grobbelaar

D. Winckelmann · F. Bleeke

Jacobs-University Bremen, School of Engineering and Science, Campus Ring 1, 28759 Bremen, Germany

D. Winckelmann $(\square) \cdot$ F. Bleeke $\cdot$ B. Thomas · C. Elle · G. Klöck

University of Applied Sciences Bremen, Am Neustadtswall 30, 28199 Bremen, Germany

e-mail: d.winckelmann@jacobs-university.de 
2010). Another reason for the loss of revenue are weed algae overgrowing the algae to be produced. Weed algae are indigenous algae more suitable for the conditions at the production site (Becker 1994). Depending on the final use of the algae biomass, even small amounts of foreign algae can render an algae culture unsuitable for further processing (Gilroy et al. 2000; Gantar and Svirčev 2008).

The use of indigenous species as production strains is said to reduce the risk of culture loss. Their origin at the same climate as the production site will reduce the risk of culture crash due to climatological and other abiotic factors, and it is assumed that they will be able to outcompete or at least suppress other indigenous algae (Mutanda et al. 2011; Odlare et al. 2011; Rawat et al. 2013).

The aim of this study was to test if indigenous algae grown in industrial waste water can be grown on nonarable land in an arid region.

The crude oil production in the al-Wusta region of the Sultanate Oman results in $800,000 \mathrm{~m}^{3}$ production water per day (Breuer and Al-Asmi 2010). A fraction of approximately 100,000 $\mathrm{m}^{3}$ is treated in a reed bed water treatment plant in Nimr. Uses for the resulting hydrocarbon-free brackish water (pPW) to increase revenue are sought for and the location of Nimr being a semi-arid region led to the consideration to establish an algae production facility.

In February 2014, an open pond culture of Cyanobacterium aponinum grown in Nimr was invaded by green algae. The algae used for this study, Scenedesmus Sp. (SC) strain MKB, was isolated from the mixed culture.

To evaluate the stability of the production process, SC was grown in 2013 and 2014. The productivity and the overall efficiency of photon capture (Grobbelaar 2009) were chosen as an indicator for the efficiency of the production process. The introduction of weed algae might lead to unwanted competition for nutrients and sunlight. It was monitored microscopically and using a multi-channel pulse-amplitude-modulation chlorophyll fluorometer [PAM; (Kolbowski and Schreiber 1995)].

\section{Methods}

Analytical methods

Temperature $\left({ }^{\circ} \mathrm{C}\right)$, wind velocity $(\mathrm{m} / \mathrm{S})$, and light intensity $\left(\mathrm{W} / \mathrm{m}^{2}\right)$ were measured by an adjacent weather station (data kindly provided by Bauer Nimr LLc). Light $\left(\mu \mathrm{mol}\right.$ photons $/ \mathrm{m}^{2} / \mathrm{s}$ ) was measured using a Mini Quantum Sensor MQS-B (Heinz Walz GmbH, Germany). A conversion factor from W/m $/ \mathrm{m}^{2}$ to $\mu$ mol photons/ $\mathrm{m}^{2} / \mathrm{s}$ of 2.9 was calculated. The mass transfer coefficient for oxygen $\left[\mathrm{k}_{\mathrm{L}} \mathrm{a}\left(\mathrm{O}_{2}\right)\right]$ of the open ponds was determined using the dynamic method (Doran 1995). The $\mathrm{k}_{\mathrm{L}} \mathrm{a}\left(\mathrm{O}_{2}\right)$ can be used to quantify the oxygen transfer from the liquid phase to the surrounding air. It is also used to calculate the $\mathrm{k}_{\mathrm{L}} \mathrm{a}\left(\mathrm{CO}_{2}\right)$ using the equations from Talbot et al. (1990). Flow velocity inside an open pond was measured using a current meter (C2 with a $30 \mathrm{~mm}$ blade (gradient 0.1) and counter Z30 OTT Hydromet GmbH, Germany).

The biomass was measured by means of optical density at $660 \mathrm{~nm}$ (Lovibond MaxiDirect photometer, Tintometer GmbH, Germany). Culture composition was determined microscopically (using a Zeiss Axiostar Plus light microscope, Carl Zeiss GmbH, Germany) and a Thoma Neu chamber with a depth of $0.1 \mathrm{~mm}$ (Paul Marienfeld GmbH \& Co. KG, Germany). For the determination of bio dry weight (dw), part of a culture was washed and filtered. The filter was dried at $105{ }^{\circ} \mathrm{C}$ until the weight was constant. Increase of salinity was measured by means of conductivity (Water quality meter U-52, Horiba Ltd., Japan). The photosynthetic yield $(Y)$ and all photosynthetic parameters were measured using a phyto-PAM with phyto-EDF (Heinz Walz $\mathrm{GmbH}$, Germany) as described previously (Winckelmann et al. 2014). Rapid light curves (Ralph and Gademann 2005), the illumination of a sample with increasing light intensities, were measured to estimate the photosynthetic performance. Thereby, light intensities from 0 to $197 \mu \mathrm{mol}$ photons $/ \mathrm{m}^{2} / \mathrm{s}$ were used in nine steps lasting 1 min each.

Isolation and characterization

Scenedesmus Sp. MKB was isolated from Cyanobacterium aponinum cultures and characterized as described earlier (Winckelmann et al. 2014). It was identified as described earlier (Winckelmann et al. 2014) using 
primer pair ITS4 and ITS5 (Connell 2000) (Results: GenBank KM873329) and EukA and EukB without GCclamp (Medlin et al. 1988) (results: GenBank KM873328).

Biomass growth for inoculation

The initial inoculum was cultured in Wuxal-media (Winckelmann et al. 2014) until a biomass of above $0.5 \mathrm{~g}$ dry weight/L was reached. The cultures were transferred to $1.5 \mathrm{~L}$ bottle reactors which were situated outside; the place selected was in full sunlight until midday and covered in shade afterward. The cultures were aerated with a rate of $30 \mathrm{~L} / \mathrm{h}$. For the first 4 days of outdoor cultivation, unsterilized bottled water with $0.05 \%(\mathrm{v} / \mathrm{v})$ Wuxal (Wuxal ${ }^{\circledR}$ Universaldünger liquid plant fertilizer, Wilhelm Haug GmbH \& Co. KG, Germany) was used as growth media. The cultures were divided each time so the biomass reached a dry weight of above $0.5 \mathrm{~g}$ dry weight/L and diluted with unfiltered (2013) or filtered (2014) pPW. The experiment performed in April 2014 was inoculated with sedimented culture from the experiment conducted in March 2013.

Production site and composition of produced water

Algae ponds were constructed on site of the Bauer Nimr water treatment plant(Abed et al. 2014). The growth media used was made up of pPW $\left(440-550 \mathrm{mg} / \mathrm{L} \mathrm{SO}_{4}, \mathrm{~N}-\mathrm{NH}_{3} 0.3-0.6 \mathrm{mg} / \mathrm{L}, \mathrm{N}-\mathrm{NO}_{3} 0.2-1.0 \mathrm{mg} / \mathrm{L}, \mathrm{P}-\mathrm{PO}_{4}\right.$ $<0.2 \mathrm{mg} / \mathrm{L}$, salinity 7-12 ppt; analysis kindly provided by Bauer Nimr LLc; values measured before the addition of fertilizer) and $0.5 \%(\mathrm{v} / \mathrm{v})$ Wuxal.

Pond construction

Open ponds ( $4 \mathrm{~m}$ long, $80 \mathrm{~cm}$ wide, and $38 \mathrm{~cm}$ deep) were constructed on a leveled area. Building bricks (39 cm long, $19 \mathrm{~cm}$ wide, and $19 \mathrm{~cm}$ deep) were used for the outer walls and $2 \mathrm{~mm}$ thick high density polyethylene (HDPE) sheets were used as liner. A centrifugal pump ( 2 in. diameter; Pedrollo, HFm 5AM) was used for mixing.

Biomass production in open ponds

Growth experiments were conducted with a volume of $600 \mathrm{~L}$. The growth medium used was pPW, which was left standing for at least 2 days in a one cubic meter container, only the top $70 \%$ was used as feed water and $0.05 \%(\mathrm{v} / \mathrm{v})$ Wuxal was added directly into the pond. The ponds were filled to a depth of $20 \mathrm{~cm}$ and inoculated with $18 \mathrm{~L}$ inoculum (biomass content of at least $1 \mathrm{~g}$ dry weight/L). The cultures were mixed $24 \mathrm{~h}$ per day if not stated otherwise.

\section{Harvesting}

Part of the culture was exchanged on a regular basis. Therefore, the culture was removed until the depth was $10 \mathrm{~cm}$. Fresh pPW containing $0.05 \% \mathrm{v} / \mathrm{v}$ fertilizer was added until a depth of $20 \mathrm{~cm}$ was reached, and on days without removal the evaporated water was replaced with fresh $\mathrm{pPW}$.

\section{Results}

Environmental conditions

The light intensity during all experiments reached medium values over the course of the sunlight hours of a day, which were in between 975 and $1740 \mu$ mol photons $/ \mathrm{m}^{2} / \mathrm{s}$ and maximum values in between 2400 and $3050 \mu \mathrm{mol}$ photons $/ \mathrm{m}^{2} / \mathrm{s}$. The duration of sunlight was between 12 and $14 \mathrm{~h}$ per day. The maximum temperature was between 29.9 and $41.9^{\circ} \mathrm{C}$ (Fig. 1). The monthly mean temperatures did not differ significantly between 2013 and 2014. The monthly mean and maximum light intensities were 770 and 3030 in March 2013 and 810 and 3010 in April 2013. These values were higher than the recorded values of 2014 which were 730 

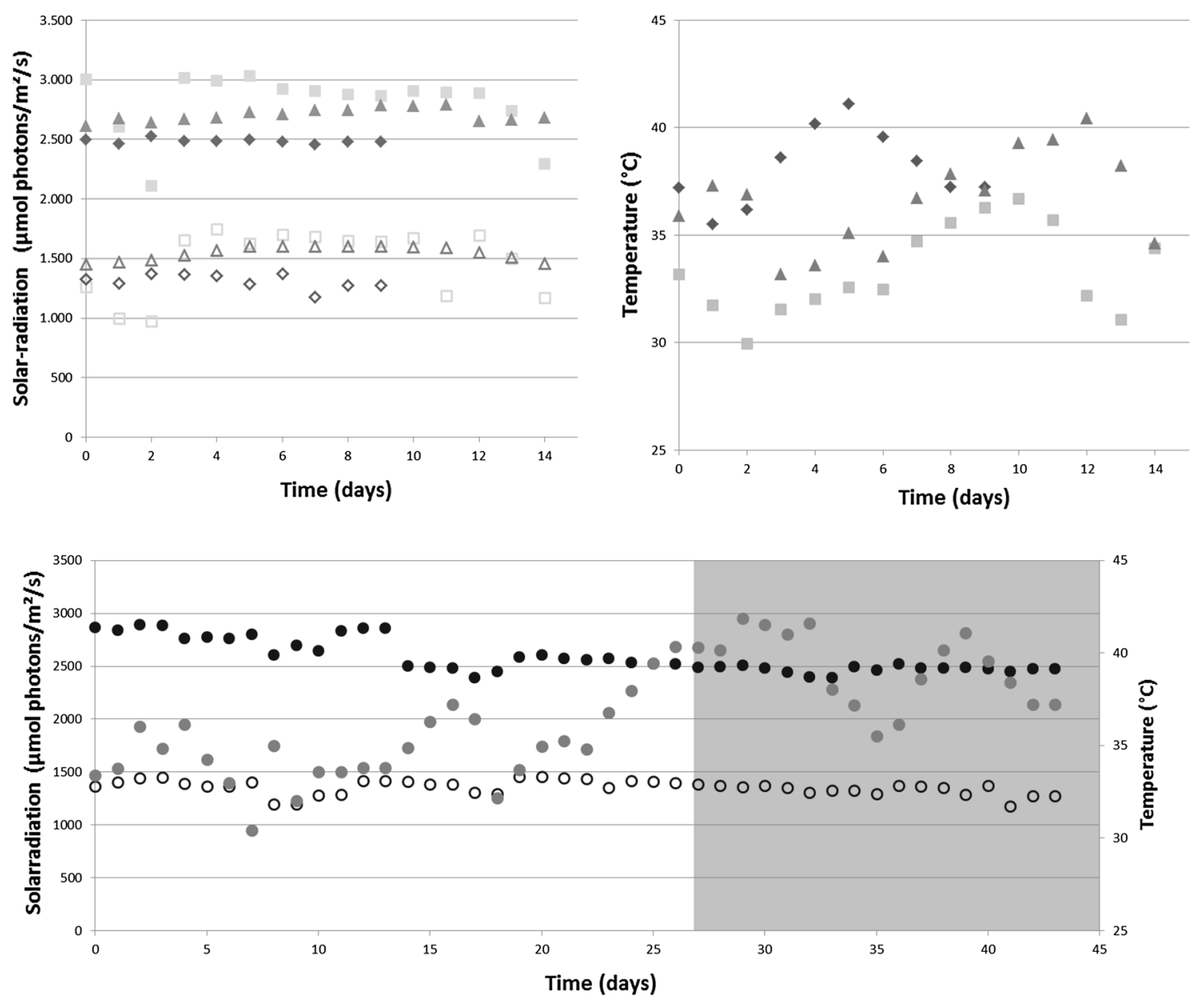

Fig. 1 Progression of light intensity and temperature. Top row shows three experiments (square March 2013; triangle April 2013; diamond April 2014) with durations of 14 days or less; left light intensity (solid symbols maximum intensity, open symbols medium intensity); right maximum temperature. Lower row shows the maximum light intensity (black solid circle), medium light intensity (black open circle), and maximum temperature (gray-closed circle) of a growth experiment lasting 43 days (MarchApril 2014). The area shaded in gray indicates a decreased water circulation

and 2890 in March and 710 and 2430 in April (all measurements in $\mu$ mol photons $/ \mathrm{m}^{2} / \mathrm{s}$ ). During both periods, days with dust or cloud coverage were observed (9 days in 2013 and 5 days in 2014). Heavy winds and dust led to the termination of the experiment in March 2013.

Open pond characteristics

To be able to assess $\mathrm{CO}_{2}$ supply, oxygen degassing, and biomass sedimentation, the open pond characteristics were determined. The ponds showed a $\mathrm{k}_{\mathrm{L}} \mathrm{a}\left(\mathrm{O}_{2}\right)$ value of $0.04 / \mathrm{s}(\mathrm{SD} \pm 0.01)$, a $\mathrm{k}_{\mathrm{L}} \mathrm{a}\left(\mathrm{CO}_{2}\right)$ of $0.033 / \mathrm{s}$, and current velocities $5 \mathrm{~cm}$ above the ground were between 0.2 and $2.3 \mathrm{~m} / \mathrm{s}$ (Fig. 2).

Culture composition

The cultures were examined microscopically to observe the influence of weed algae or grazers on the culture's stability. The culture's health was examined using the chlorophyll fluorescence as the parameter. We found that all cultures were mixed cultures and bacteria were found. During all experiments, three different groups of photosynthetic active organisms were found (Fig. 3) in different abundance (Fig. 4). In single cases during pump outage, the appearance of small dark brown flakes, with small air bubbles attached to it, on the surface 


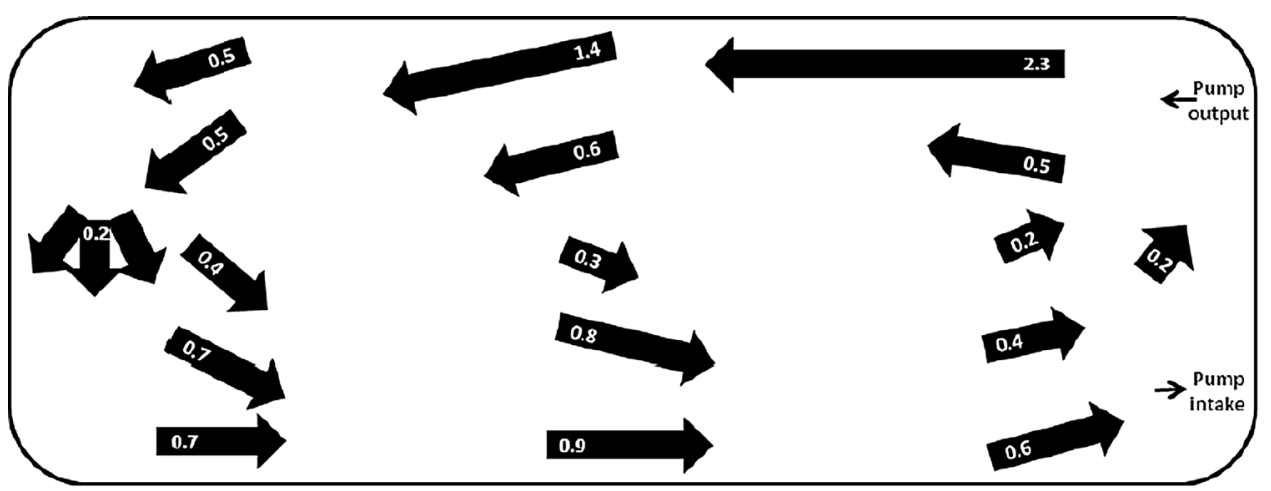

Fig. 2 Flow velocities and directions in open pond. Unit $\mathrm{m} / \mathrm{s}$. Measurement depth was $5 \mathrm{~cm}$ above the bottom. Pond length $4 \mathrm{~m}$, pond width $0.8 \mathrm{~m}$, water level $20 \mathrm{~cm}$. Figure is not up to scale
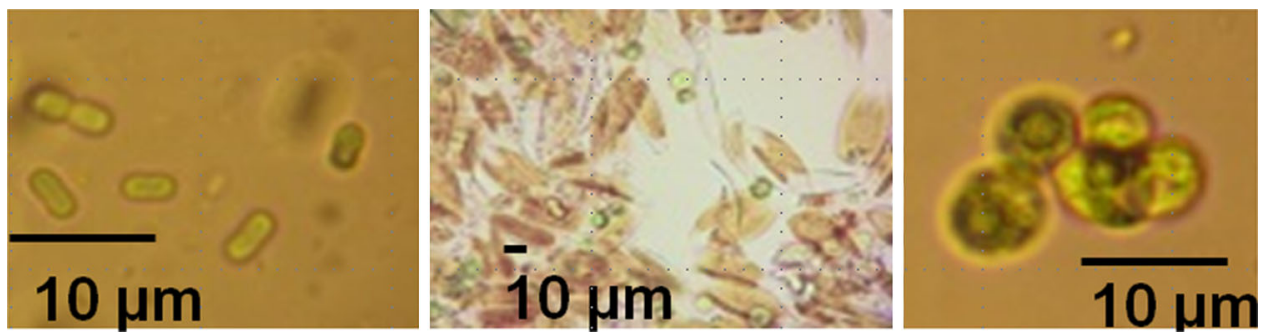

Fig. 3 Photosynthetically active organisms found in all growth experiments; from left to right: single-celled cyanobacteria, most likely Cyanobacterium aponinum; Diatoms; Scenedesmus spec
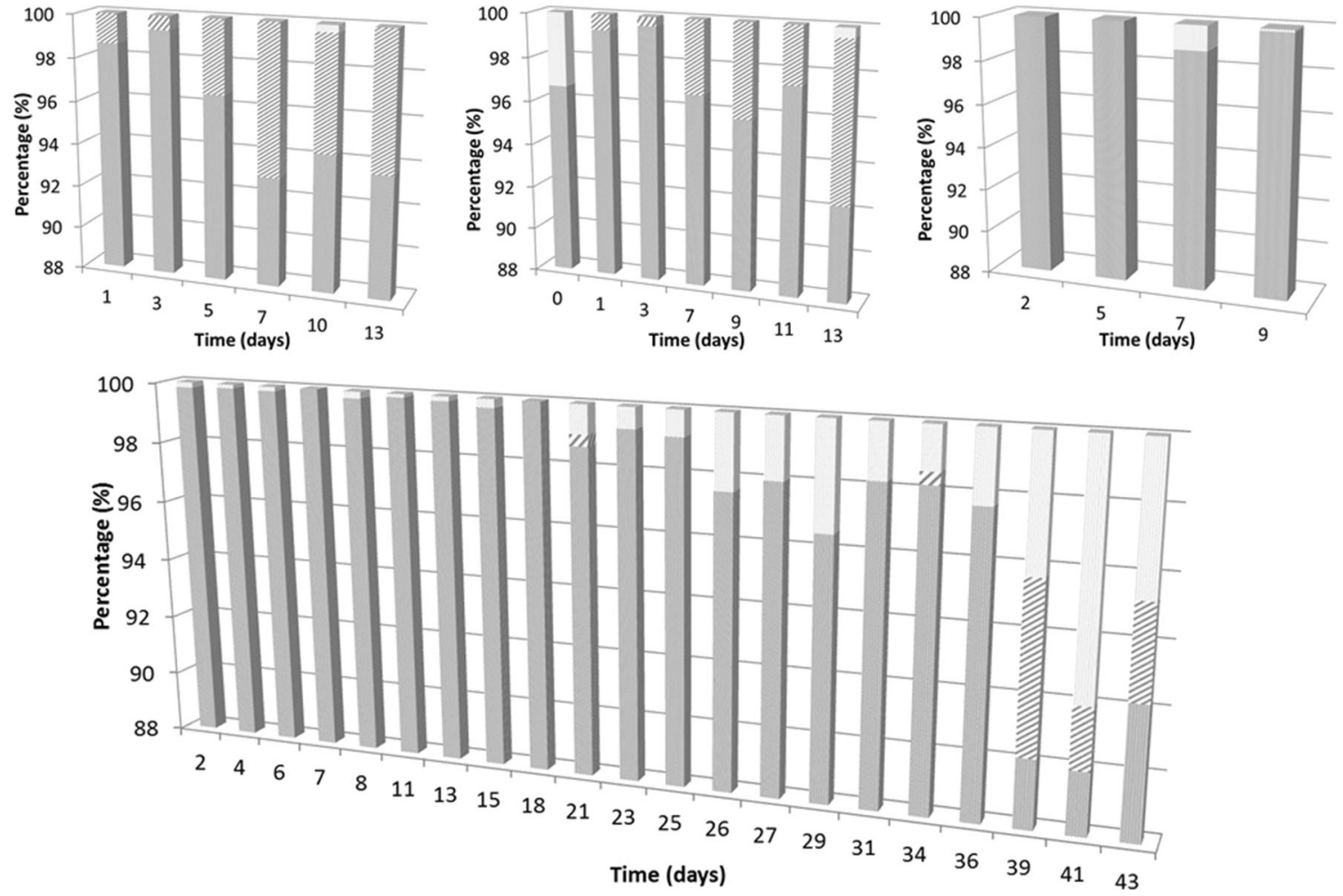

Fig. 4 Distribution of different photosynthetic active groups over time. First row left experiment March 2013; middle experiment April 2013; right experiment April 2014; lower row March-April 2014. Graphs show the microscopically determined share of Scenedesmus (gray, bottom), Diatoms (stripes, middle), and cyanobacteria (white, top) 
of the culture was observed. The flakes and swabs from biofilms formed in pond regions with insufficient water movement were microscopically observed and showed a mixture of organisms and inorganic particles dominated by diatoms (Fig. 5). The amount of biofilm formed was not evaluated.

The maximum photosynthetic yield of all cultures increased above 0.7 during the first 2 days of cultivation, and it decreased right after a harvest was performed but recovered within hours. The non-photochemical quenching (NPQ) increased in the beginning above two. The overall photosynthetic characteristics in the morning, before dilution, did not differ significantly in between experiments (Table 1).

The experiment conducted in March 2013 showed signs of contamination from the early beginning. It was contaminated with diatoms and the contamination concentration breached the two percent threshold on day 5 and on the same day decreased $Y$ below 0.7 and the maximum NPQ reached only 1.5 (Fig. 6). After the restart of the experiment in April 2014, the culture showed a high contamination with cyanobacteria on the day of inoculation; however, over the course of the cultivation nearly no cyanobacteria were detected until day 13 . Although diatoms were detected on day 1 and after day 5, $Y$ decreased below 0.7 and the maximum NPQ did only reach a maximum of around 1.5 after day 7 .

The experiment conducted in April 2014 showed no sign of contamination in the beginning but a small amount of cyanobacteria was observed on day 7 and decreased until day 9. No change in $Y$ or NPQ was observed.

The experiments conducted in March and April 2014 were contaminated with cyanobacteria and diatoms from the early beginning. While the diatoms were nearly undetectable using a microscope, the concentration of cyanobacteria breached the two percent threshold on day 26. The pump failed and had to be replaced with a smaller one, which only had 20 percent of performance rate on day 27 (part in Figs. 1, 3, 6, 7 lower row, which is underlayed gray). On day 36, the $Y$ dropped permanently under 0.7 and the diatom concentration became detectable on day 39. The maximum NPQ was between 1.5 and 2 for most part of this experiment but dropped to values below 1 after day 36 .

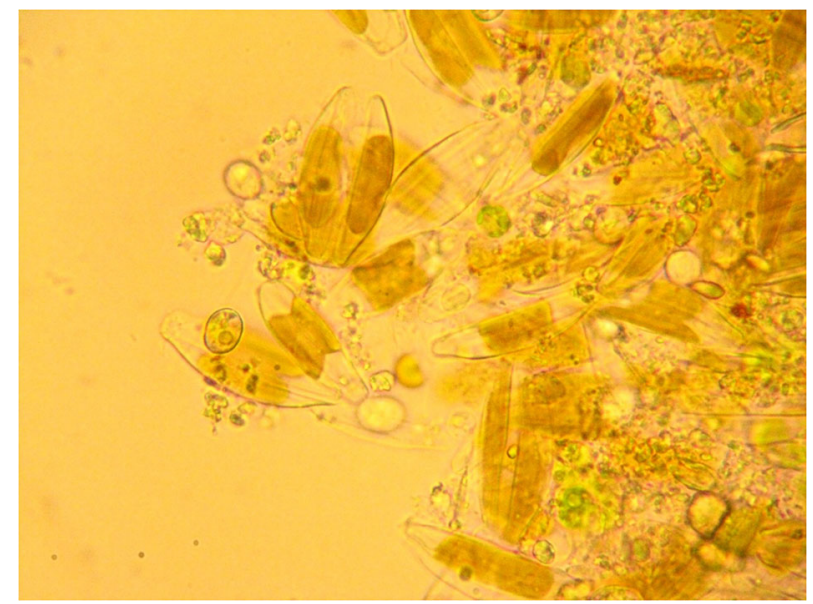

Fig. 5 Exemplary picture of community found in biofilm developed in regions with insufficient culture movement

Table 1 Overall photosynthetic performance as determined using photosynthesis-irradiance curves

\begin{tabular}{lccccc}
\hline & March 2013 & April 2013 & April 2014 & March-April 2013-till day 27 & March-April 2013-after day 27 \\
\hline Alpha (SD) & $0.27(0.02)$ & $0.26(0.02)$ & $0.32(0.07)$ & $0.30(0.01)$ & $0.28(0.03)$ \\
$I_{\mathrm{K}}(\mathrm{SD})$ & $14(3)$ & $12(5)$ & $16(2)$ & $14(2.6)$ & $17(5)$ \\
$P_{\max }(\mathrm{SD})$ & $51(12)$ & $47(18)$ & $52(13)$ & $45(10)$ & $61(19)$ \\
\hline
\end{tabular}

All data were measured in the morning between 9 and 10 a.m. before dilution of the culture. Data are not normalized against biomass

Alpha maximum light use coefficient for photosystem II, $I_{K}$ transition point between light limited and light saturated photosynthesis, $P_{\max }$ maximum photosynthetic rates 

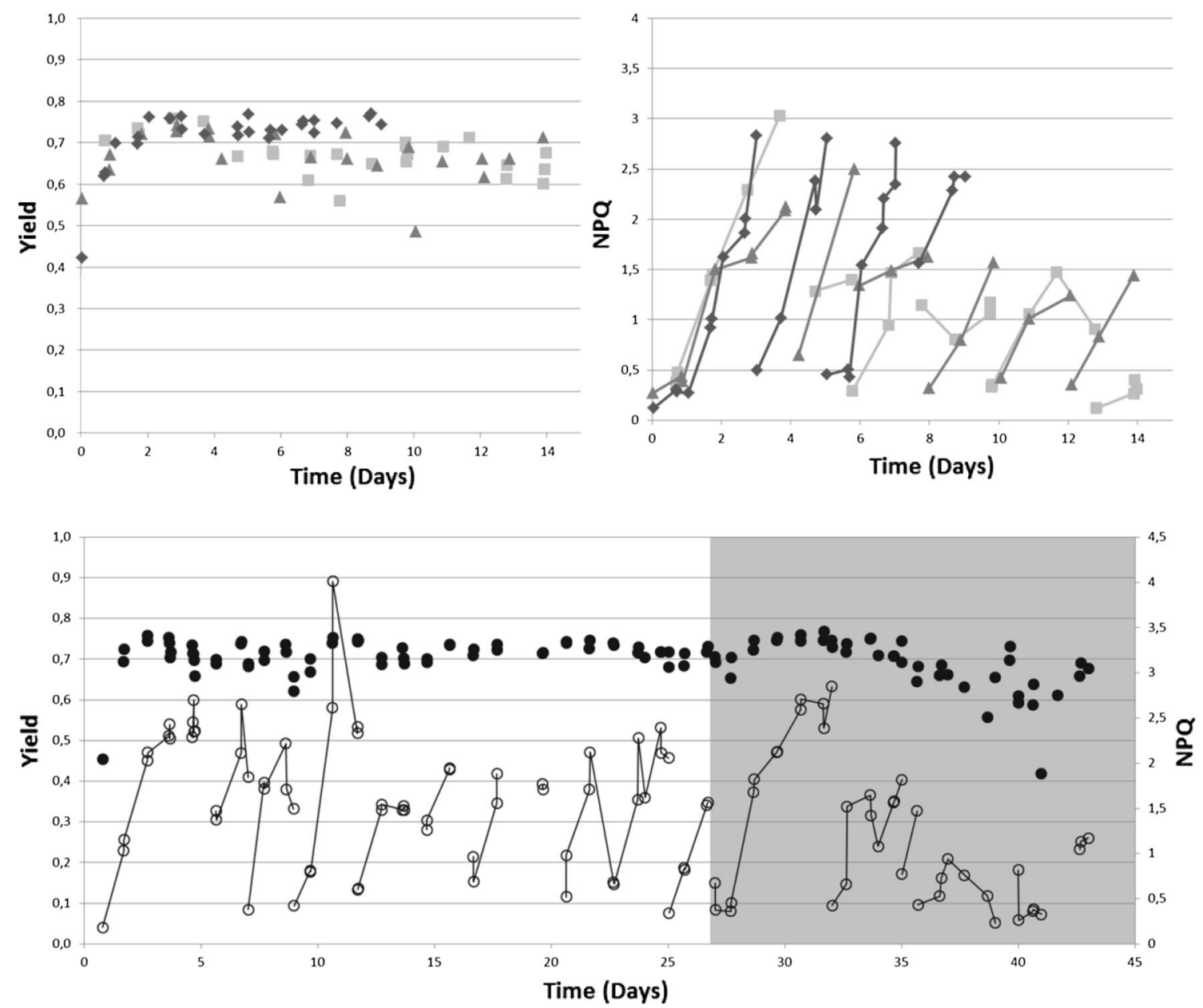

Fig. 6 Development of maximum quantum yield and non-photochemical quenching over time; samples were dark adapted for $5 \mathrm{~min}$. Light of a wavelength of $645 \mathrm{~nm}$ was used for excitation. Unlinked data points in NPQ indicate dilution of the culture. Top row shows three experiments (square March 2013; triangle April 2013; diamond April 2014) with durations of 14 days or less; Left maximum quantum yield; right NPQ. Lower row shows the maximum quantum yield (black solid circle) and NPQ (black open circle) of a growth experiment lasting 43 days (March-April 2014). The area shaded in gray indicates a decreased water circulation

Productivity and media parameter

The overall biomass productivity and the $\mathrm{pH}$ and conductivity of the culture media were measured to determine the influence of a high $\mathrm{pH}$ and the salinity to be reached on the productivity.

All growth experiments were harvested every other day (Fig. 7) and showed a mean productivity of $16.1 \mathrm{~g} /$ $\mathrm{m}^{2} /$ day $(\mathrm{SD} \pm 1.7)$ in 2013 and $15.4 \mathrm{~g} / \mathrm{m}^{2} /$ day $(\mathrm{SD} \pm 4.7)$ in 2014 . The $\mathrm{pH}$ showed values of between 8.3 and 10.0 in the morning (Fig. 7) rising between 0.6 and 0.8 points over the day and decreasing overnight. The conductivity alternated during all experiments in various degrees between 15 and $25 \mathrm{mS} / \mathrm{cm}$ depending on the conductivity of the feed water. The dilution of the culture led to a drop in $\mathrm{pH}$, and after addition of fertilizer the slope of $\mathrm{pH}$-increase declined. The maximum measured $\mathrm{pH}$-values of all cultures were in the afternoon after a full day of growth between 10.1 and 10.8.

During the different experiments, the circulation of the cultures stopped irregularly due to the maintenance of the generator or failure of mechanical parts (March 2013: $21 \mathrm{~h}$ in 14 days; April 2013: $3 \mathrm{~h}$ in 14 days; April 2014: $31 \mathrm{~h}$ in 9 days; March-April 2014: $82 \mathrm{~h}$ during the first 27 days and $31 \mathrm{~h}$ during the 16 days with reduced pump performance). Single power outages lasted as long as 3-12 h. During this time, no decrease in productivity was observed but the $\mathrm{pH}$ of cultures increased faster and if stopped longer than $6 \mathrm{~h}$ from the morning on it plateaued at values around $10.3(\mathrm{SD} \pm 0.1)$. 

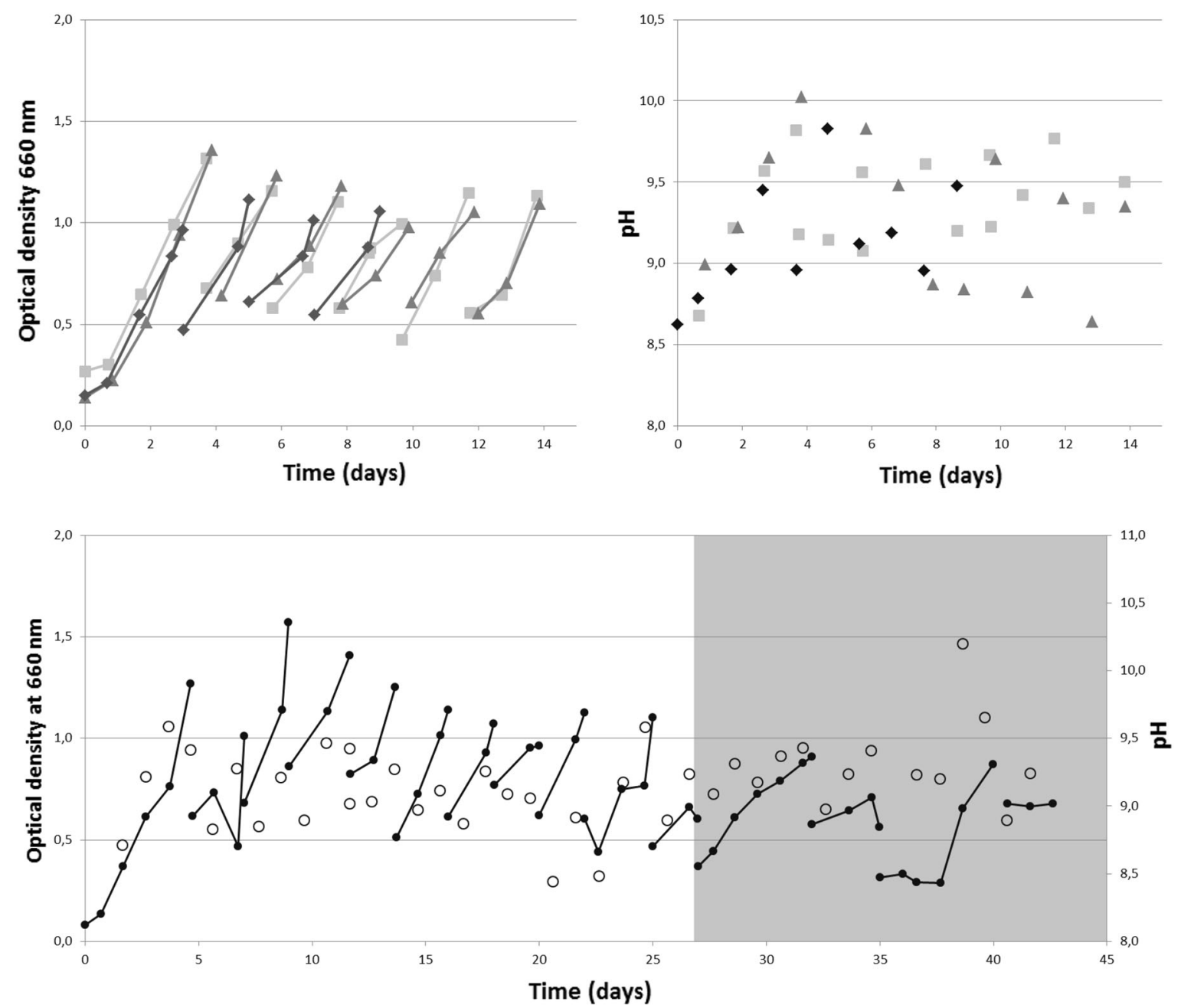

Fig. 7 Growth behavior of Scenedesmus Spec. MKB in 600L pre-cleaned PW while diluted by ca. $50 \%$ every other day. Fertilizer was added after each harvest. Biomass increase is shown as determined by optical density measurement, unlinked data points indicate dilution. The $\mathrm{pH}$ shows only the mean values of 3 min measured in the morning between 8 and 10 a.m. Top row shows three experiments (square March 2013; triangle April 2013; diamond April 2014) with durations of 14 days or less; left biomass; Right $\mathrm{pH}$. Lower row shows the biomass (black solid circle) and $\mathrm{pH}$ (black open circle) of a growth experiment lasting 43 days (March-April 2014). The area shaded in gray indicates a decreased water circulation

The productivity of the experiment conducted in March and April 2014 dropped to $6.3 \mathrm{~g} / \mathrm{m}^{2} / \mathrm{day}$ (SD \pm 2.0 ) when the pump was replaced by a smaller one on day 27 .

\section{Discussion}

Culture composition

The biomass monitored in 2013 was contaminated by weed algae, mainly diatoms, from the early beginning. This is accounted to the lack of a suitable filtration system for treatment of the pPW. The change in biomass composition from the end of the experiment in March 2013 and the beginning culture composition of the experiment performed in April 2013 showed that a significant amount of diatoms was removed from the culture via sedimentation. In 2014, diatoms were not detected (April 2014) or the earliest after 3 weeks of growth (March-April 2014), while single-celled cyanobacteria were detected in small amount during most parts of the experiments. The possible use of photosynthetic characteristics for the detection of weed algae was 
examined in more detail. The maximum values of NPQ decreased when the culture matured and the maximum NPQ of the experiment in April 2014 stayed around 2.5; the NPQ of all other experiments declined. An axenic culture of Cyanobacterium aponinum grown under the same circumstances had a NPQ of 0.5 which increased with invading green algae and diatoms (Paper submitted for publication). During times when the NPQ did not increase as high as before, the photosynthetic yield decreased as well. The photosynthetic yield $(Y)$ was proven to be influenced by numerous different factors like nutrients (Lippemeier et al. 2001), light, culture density (Schreiber and Klughammer 2013), and salt stress (Lu and Vonshak 2002) and culture composition (Kolbowski and Schreiber 1995). Since measurements were taken daily at the same time, we do not consider the difference of daylight intensity between measurement days to be a considerable influence. The culture density and the salt content of the experiment conducted April 2014 alternated in between OD 0.5 and 1.3 and $15-25 \mathrm{mS} / \mathrm{cm}$, respectively, but no significant change in $Y$ was monitored, it was therefore concluded that cell density and salinity seem to have only a small influence at best. Nutrients were added after every dilution and it is assumed that they were available in abundance. $Y$ is influenced by toxic substances as well (SchmittJansen and Altenburger 2008; Peña-Vázquez et al. 2010), and algae cultures are suspected to accumulate physiological products inside the medium, which might inhibit growth (Gustavs et al. 2010). It was concluded that, since the change in Y during the trial conducted in March-April 2014 occurred after 34 days, the buildup of inhibiting physiological byproducts will be neglected. Cyanobacteria and diatoms showed during laboratory studies (Winckelmann et al. 2014) a maximum $Y$ of 0.45 and 0.6, respectively. The change in $Y$ occurred within 2 days of the microscopically detected weed algae, it is thought the lower capability of cyanobacteria and diatoms to use light energy for fluorescence might lead to a quenching of the overall $Y$.

The use of the phyto-PAM for the detection of weed algae and overall stress in an open pond as a standalone method is not advised. While it would be possible to establish an online sensor, it would be influenced by a range of different factors and the growth system to be monitored has to be well understood. A welltrained operator might be capable to distinguish the influence of nutrient deprivation from the afternoon photoinhibition(Lu and Vonshak 1999), but the sensitivity is insufficient to detect weed algae in an early stage. While it was possible to detect cyanobacteria concentration of $5 \times 10^{\wedge} 3$ cells $/ \mathrm{mL}$ cells $/ \mathrm{mL}$ in $2.5 \times 10^{\wedge} 6$ cells $/ \mathrm{mL}$ with a microscope, the phyto-PAM started to detect cyanobacteria at $5 \times 10^{\wedge} 4 \mathrm{cells} / \mathrm{mL}$. Other techniques for the detection of weed algae and even non-photosynthetic organisms like grazers can be applied (Havlik et al. 2013a). Flow cytometry was found to detect weed algae with a concentration as low as $0.01 \%$ (Fulbright et al. 2014), and even capable to monitor algae; which change shape during their growth cycle (Havlik et al. 2013b). Real-Time quantitative PCR (qPCR) could be used to monitor production systems as well; qPCR systems were able to detect known possible contaminants at levels of $0.00001 \%$ (Fulbright et al. 2014).

Grazers were only detected in matured cultures living in the biofilm; the abundance was too low to be quantified. Only bacteria grazing was monitored. It is assumed that the high $\mathrm{pH}$ and temperature did minimize the growth of grazers (Bartley et al. 2013).

\section{Productivity}

The overall production of all experiments, excluding the lag phase and the time with reduced pump performance, was $15.7 \mathrm{~g} / \mathrm{m}^{2} /$ day $(\mathrm{SD} \pm 3.6$ ). The average light intensity in Oman was reported to be around $1800 \mu \mathrm{mol}$ photons $/ \mathrm{m}^{2} / \mathrm{s}$ (Al-Rawahy et al. 2003). Values of around $1500 \mu \mathrm{mol}$ photons $/ \mathrm{m}^{2} / \mathrm{s}$ were measured during this study. Using the calculations proposed by Grobbelaar (2009) and assuming $40 \%$ of algal biomass to be carbon, the photosynthetic efficiency was $2.4 \%$ and decreased to $1 \%$ during prolonged periods of reduced mixing.

There are no data on Scenedesmus productivity comparable to the set-up used during this study. The productivity of a non-axenic Scenedesmus obliquus dominated culture was reported to range from $1.7 \mathrm{~g} /$ $\mathrm{m}^{2} /$ day to $16.92 \mathrm{~g} / \mathrm{m}^{2} /$ day in Germany (Grobbelaar et al. 1990) and a Scendesmus sp. culture was reported to have reached $28-82 \mathrm{~g} / \mathrm{m}^{2} /$ day (Mendoza et al. 2013). While the first study was conducted over a range of 16 months, the second was only conducted for 6 days, both used $\mathrm{CO}_{2}$ or flue gas as additional carbon sources. Weissman et al. (1989) conducted experiments in New Mexico, under similar temperature regimes and adding $\mathrm{CO}_{2}$ productivities of $33 \mathrm{~g} / \mathrm{m}^{2} /$ day, reaching the photosynthetic efficiency of $6.7 \%$. 
The overall photosynthetic characteristics as measured in the morning (Table 1) did not change significantly with increasing sun light, biomass density, or biomass composition, so it is assumed that the sun light is not the limiting factor during the growth experiments. However, the culture's Y usually declined over the course of the day (data not shown) indicating light inhibition or damage. An alteration of the pond design might lead to a decrease in light inhibition and thereby increasing the productivity(Vonshak et al. 2013), also the ability to cope with excess light of high intensity varies over the experiment. After the inoculation and dilution, the NPQ was below 0.5 but increased up to 3 before the next dilution. The drop in NPQ can be explained by the dilution and the decreased biomass concentration reducing the cultures self-shading (Küster et al. 2004).

It is hypothesized that the high $\mathrm{pH}$ plays a major role in the limitation of growth. The availability of carbon as substrate for photosynthesis is crucial. The maximum concentration of carbon dioxide in liquid with a salt content of $1 \% \mathrm{w} / \mathrm{v}$ is $1.2 \mathrm{~g} / \mathrm{L}$ at $30{ }^{\circ} \mathrm{C}$ (Duan and Sun 2003). With the measured $\mathrm{k}_{\mathrm{L}} \mathrm{a}\left(\mathrm{O}_{2}\right)$, not only would be all oxygen produced during photosynthesis be transferred out of the media, but the high $\mathrm{k}_{\mathrm{L}} \mathrm{a}\left(\mathrm{CO}_{2}\right)$ would be sufficient to supply a constant stream of carbon. On the supposition of a gradient favoring the transition of $\mathrm{CO}_{2}$ from air to liquid and using the calculations provided by Talbot et al. (1990), a maximum of $143 \mathrm{~g}$ of carbon dioxide could be transferred per hour into a 600 liter culture in the ponds described above.

The uptake of $\mathrm{HCO}_{3}{ }^{-}$and $\mathrm{CO}_{2}$ can occur simultaneously in some green algae via different pathways, leading to $\mathrm{OH}^{-}$formation and alkalization of the medium, even if $\mathrm{CO}_{2}^{(\text {aq. }}$ is present. See Badger and Price for a review regarding the $\mathrm{CO}_{2}$ concentrating mechanism (Badger and Price 1992). Six different green algae have shown to stop photosynthesis at a pH above 10 (Shiraiwa et al. 1993) at which most of the dissolved inorganic carbon has the form of $\mathrm{CO}_{3}{ }^{2-}$ (Markou et al. 2014). $\mathrm{pKa}$ of $\mathrm{CO}_{3}{ }^{2-}$ is 10.3 at $25{ }^{\circ} \mathrm{C}$ but decreases with increasing temperature (Rabinowitch 1945). $\mathrm{CO}_{3}{ }^{2-}$ is unavailable for most microalgae (Markou et al. 2014). While it is known that Scenedesmus and some marine algae are capable of thriving at $\mathrm{pH}$ of 8-9, it is unknown how the excess $\mathrm{CO}_{3}{ }^{2-}$ influences the growth (Shiraiwa et al. 1993).

Scenedesmus obliquus showed an increase of lipid content after addition of $5 \mathrm{~g} / \mathrm{L} \mathrm{NaCl}$ (Gorain et al. 2013) but were also negatively influenced by further increased $\mathrm{NaCl}$ level (Affenzeller et al. 2009; Salama et al. 2013). The $\mathrm{NaCl}$ level reported as being sufficient for repressing growth had a conductivity of $11.1 \mathrm{mS} / \mathrm{cm}$ (Salama et al. 2013). No work about salt stress and green algae isolated from brackish water was found. The fluctuating salinity during this experiment was always higher than $15 \mathrm{~m} / \mathrm{S} / \mathrm{cm}$, but no significant correlations between conductivity and productivity were found.

Economic feasibility and suggested improvements

If algae were to be produced under similar conditions as experienced during this study and the production facility would have a pond surface of $80 \%$ and could operate on 300 days per year, it would produce 28 tons (dw) biomass per year. It was shown that Scenedesmus sp. biomass, grown phototrophically outdoors in Arizonas climate, consisted of $42 \%(\mathrm{dw})$ carbohydrates [7 \% (dw) were starch], $15 \%(\mathrm{dw})$ lipids, and $27 \%$ (dw) proteins, which was altered after 14 days of nutrient depletion to $45 \%(\mathrm{dw})$ carbohydrates $(20 \%(\mathrm{dw})$ were starch), $30 \%$ (dw) lipids, and $10 \%$ (dw) proteins (Laurens et al. 2014). Under different conditions, lipid accumulations as high as $53 \%(\mathrm{dw})$ were reported (Xin et al. 2010). The lipid composition of Scenedesmus sp. has been reported to be suitable for biodiesel production (Gouveia and Oliveira 2009; Makarevi et al. 2011; Jena et al. 2012). If Scenedesmus sp. grown in pPW would have the same composition as shown after growth in modified BG-11 media(Laurens et al. 2014), it would be possible to harvest $9500 \mathrm{~L}$ of lipids (assuming a density of $800 \mathrm{~g} / \mathrm{L}$ ) leading to $7600 \mathrm{~L}$ of biodiesel per hectare per year (Chisti 2007). This would be only a fraction of the 58,700 L/ha/year predicted, but still higher than the oil yield reported for palm oil (Chisti 2007). There are multiple possibilities to increase productivity and to make the production of green algae on site more sustainable. The biomass residues not sold can be digested for biogas, which can be used as $\mathrm{CO}_{2}$ and energy source, while the residues can be used instead of fertilizer (Chisti 2013). A change in the mixing system will change the productivity; the use of a centrifugal pump as opposed to a paddle wheel will lead to a well-mixed culture and a high turbulence which is stated to prevent algal sedimentation, nutritional gradients, and to expose the algae to variations in the quantity and quality of light (Grobbelaar 2010). But it is also less energy efficient. The floating of algae flocks at times of pump failure showed that there was a biofilm formation. The biofilm mainly consisted of diatoms and dust particles and was stronger in areas with less 
turbulence. It is strongly suggested that the biofilm formation is influenced by the amount of dust, the turbulence of the culture, and the roughness of the pond liner. A change in pond design or mixing might lead to less biofilm formation and thereby reduce the risk of product contamination. It was shown that wave formation inside of a pond led to an increased productivity and a better nitrogen uptake (Chiaramonti et al. 2013). If wave formation would be obtained by intermittent reduction of the pumps delivery rate, a decrease in energy consumption might be achieved.

A final statement of economic feasibility is not possible at this stage. The energy consumption for all steps involved in upstream and downstream processing has to be included into the calculation as well as possible nutrient recycling, nutrient costs, the usability of algae residues on site, and the work hours to be invested (Collet et al. 2013).

\section{Conclusion}

It was shown that it is possible to grow indigenous algae in open ponds in an arid region using pre-cleaned waste water as growth medium. The concerns regarding salt stress due to evaporation were unwarranted. The green algae isolated on-site were suited to the conditions of high temperature and increasing salt content, and dominated the culture, while no signs of decreasing health were detectable.

High turbulence and flow regime are necessary to ensure high production rates. The design of the ponds and the means used to establish the flow regime have to be changed during scale-up to increase or at least stabilize productivity, while reducing the applied energy and thereby make economic viability possible.

Acknowledgments The authors would like to gratefully thank Rayan Al-Kabani and Heiko Patzelt from Mazoon Environmental and Technological Services LLC, Thomas Headley, Stéphane Prigent and the whole treatment plant team of Bauer Nimr LLC for their help, time, and support, and Thomas Parry for the critical reading of the manuscript. The project underlying this report was funded by the Federal Ministry of Education and Research of Germany under grant number FHprofUnt 17003X11. The responsibility for the content of this publication lies with the author.

Open Access This article is distributed under the terms of the Creative Commons Attribution 4.0 International License (http:// creativecommons.org/licenses/by/4.0/), which permits unrestricted use, distribution, and reproduction in any medium, provided you give appropriate credit to the original author(s) and the source, provide a link to the Creative Commons license, and indicate if changes were made.

\section{References}

Abed RMM, Al-Kharusi S, Prigent S, Headley T (2014) Diversity, distribution and hydrocarbon biodegradation capabilities of microbial communities in oil-contaminated cyanobacterial mats from a constructed wetland. PLoS One 9(12):e114570. doi:10.1371/journal.pone.0114570

Affenzeller MJ, Darehshouri A, Andosch A, Lütz C, Lütz-Meindl U (2009) Salt stress-induced cell death in the unicellular green alga Micrasterias denticulata. J Exp Bot 60(3):939-954. doi:10.1093/jxb/ern348

Al-Rawahy SH, Al-Dhafri KS, Al-Bahlany SS (2003) Germination, growth and drought resistance if native and alien plant species of the genus Prosopis in the sultanate of Oman. Asian J Plant Sci 2(14):1020-1023. doi:10.3923/ajps.2003.1020.1023

Badger MR, Price GD (1992) The CO2 concentratiing mechanism in cyanobacteria and microalgae. Physiol Plant 84:606-615

Bartley ML, Boeing WJ, Dungan BN, Holguin FO, Schaub T (2013) pH effects on growth and lipid accumulation of the biofuel microalgae Nannochloropsis salina and invading organisms. J Appl Phycol 26(3):1431-1437. doi:10.1007/s10811-013-0177-2

BECKER EW (1994) Large-scale cultivation. In: Biotechnology and microbiology: microalgae. First Edition.Cambridge University Press, New York, pp 63-171

Breuer R, Al-Asmi SR (2010) Nimr water treatment project-up scaling a reed bed trail to industrial scale produced water treatment. Soc Petrol Eng SPE Int Conf Health Saf Environ Oil Gas Explor Prod 1:286-296

Chiaramonti D, Prussi M, Casini D, Tredici MR, Rodolfi L, Bassi N, Zittelli GC, Bondioli P (2013) Review of energy balance in raceway ponds for microalgae cultivation: Re-thinking a traditional system is possible. Appl Energy 102:101-111. doi:10. 1016/j.apenergy.2012.07.040 (Elsevier Ltd)

Chisti Y (2007) Biodiesel from microalgae. Biotechnol Adv 25(3):294-306. doi:10.1016/j.biotechadv.2007.02.001 (Elsevier Inc.)

Chisti Y (2013) Constraints to commercialization of algal fuels. J Biotechnol 167(3):201-214. doi:10.1016/j.jbiotec.2013.07.020 (Elsevier B.V.)

Collet P, Spinelli D, Lardon L, Hélias A, Steyer J, Bernard O (2013) Life-cycle 7 assessment of microalgal-based biofuels. In: Pandey A, Lee D-J, Chisti Y, Soccol CR (eds): Biofuels from Algae. pp 287-312, (Elsevier B.B. Amsterdam). doi: 10.1016/ B978-0-444-59558-4.00013-9 
Connell LB (2000) Nuclear ITS region of the alga Heterosigma akashiwo (Chromophyta: Raphidophyceae) is identical in isolates from Atlantic and Pacific basins. Mar Biol 136:953-960. doi:10.1007/s002270000314

Doran PM (ed) (1995) Bioprocess engineering principles, pp 129-163. doi:10.1016/B978-012220855-3/50007-9 (Elsevier B.V.)

Duan Z, Sun R (2003) An improved model calculating $\mathrm{CO}_{2}$ solubility in pure water and aqueous $\mathrm{NaCl}$ solutions from 273 to $533 \mathrm{~K}$ and from 0 to 2000 bar. Chem Geol 193:257-271. doi:10.1016/S0009-2541(02)00263-2

Fulbright SP, Dean MK, Wardle G, Lammers PJ, Chisholm S (2014) Molecular diagnostics for monitoring contaminants in algal cultivation. Algal Res. doi:10.1016/j.algal.2013.11.008 (Elsevier B.V.)

Gachon CMM, Sime-Ngando T, Strittmatter M, Chambouvet A, Kim GH (2010) Algal diseases: spotlight on a black box. Trends Plant Sci 15(11):633-640. doi:10.1016/j.tplants.2010.08.005

Gantar M, Svirčev Z (2008) Microalgae and Cyanobacteria: food for Thought. J Phycol 44(2):260-268. doi:10.1111/j.1529-8817. 2008.00469.x

Gilroy DJ, Kauffman KW, Hall RA, Huang X, Chu FS (2000) Assessing potential health risks from microcystin toxins in bluegreen algae dietary supplements. Environ Health Perspect 108(51):435-439

Gorain PC, Bagchi SK, Mallick N (2013) Effects of calcium, magnesium and sodium chloride in enhancing lipid accumulation in two green microalgae. Environ Tech 34:37-41. doi:10.1080/09593330.2013.812668

Gouveia L, Oliveira AC (2009) Microalgae as a raw material for biofuels production. J Ind Microbiol Biotechnol 36(2):269-274. doi:10.1007/s10295-008-0495-6

Grobbelaar JU (2009) Upper limits of photosynthetic productivity and problems of scaling. J Appl Phycol 21(5):519-522. doi:10. 1007/s10811-008-9372-y

Grobbelaar JU (2010) Microalgal biomass production: challenges and realities. Photosynth Res 106(1-2):135-144. doi:10.1007/ s11120-010-9573-5

Grobbelaar JU, Soeder CJ, Stengel E (1990) Modeling algal productivity in large outdoor cultures and waste treatment systems. Biomass 21(4):297-314. doi:10.1016/0144-4565(90)90079-Y

Guieysse B, Béchet Q, Shilton A (2013) Variability and uncertainty in water demand and water footprint assessments of fresh algae cultivation based on case studies from five climatic regions. Biores Technol 128:317-323. doi:10.1016/j.biortech.2012. 10.096

Gustavs L, Eggert A, Michalik D, Karsten U (2010) Physiological and biochemical responses of green microalgae from different habitats to osmotic and matric stress. Protoplasma 243(1-4):3-14. doi:10.1007/s00709-009-0060-9

Hamilton CE, Rossmeissl N, Ruddick C (2014) Exploring the utilization of complex algal communities to address algal pond crash and increase annual biomass production for algal biofuels. In: p 21

Havlik I, Lindner P, Scheper T, Reardon KF (2013a) On-line monitoring of large cultivations of microalgae and cyanobacteria. Trends Biotechnol 31(7):406-414. doi:10.1016/j.tibtech.2013.04.005

Havlik I, Reardon KF, Ünal M, Lindner P, Prediger A, Babitzky A, Beutel S, Scheper T (2013b) Monitoring of microalgal cultivations with on-line, flow-through microscopy. Algal Res 2(3):253-257. doi:10.1016/j.algal.2013.04.001 (Elsevier B.V.)

Jena J, Nayak M, Panda HS, Pradhan N, Sarika C, Panda PK, Rao VSK, Prasad BBN, Sukla LB (2012) Microalgae of Odisha coast as a potential source for biodiesel production. World Environ 2(1):12-17. doi:10.5923/j.env.20120201.03

Kolbowski J, Schreiber U (1995) Computer-controlled phyto- plankton analyzer based on a 4-wavelength PAM Chl fluoro meter. In: Mathis, P. (ed.): Photosynthesis: From Light to Biosphere. Kluwer Academic Publishers, Dordrecht

Küster A, Schaible R, Schubert H (2004) Light acclimation of photosynthesis in three charophyte species. Aquat Bot 79(2):111-124. doi:10.1016/j.aquabot.2004.01.010

Laurens LML, Van Wychen S, McAllister JP, Arrowsmith S, Dempster TA, McGowen J, Pienkos PT (2014) Strain, biochemistry, and cultivation-dependent measurement variability of algal biomass composition. Anal Biochem 452:86-95. doi:10.1016/j. ab.2014.02.009

Lippemeier S, Hintze R, Vanselow K, Hartig P, Colijn F (2001) In-line recording of PAM fluorescence of phytoplankton cultures as a new tool for studying effects of fluctuating nutrient supply on photosynthesis. Eur J Phycol 36(1):89-100. doi:10.1080/ 09670260110001735238

Lu C, Vonshak A (1999) Photoinhibition in outdoor Spirulina platensis cultures assessed by polyphasic chlorophyll fluorescence transients. J Appl Phycol 11:355-359

Lu C, Vonshak A (2002) Effects of salinity stress on photosystem II function in cyanobacterial Spirulina platensis cells. Physiol Plant 114(3):405-413. doi:10.1034/j.1399-3054.2002.1140310.x

Makarevi V, Andrulevi V, Skorupskait V (2011) Cultivation of Microalgae Chlorella sp. and Scenedesmus sp. as a potentional biofuel feedstock. Environ Res Eng Manag 57(3):21-27

Markou G, Vandamme D, Muylaert K (2014) Microalgal and cyanobacterial cultivation: the supply of nutrients. Water Res 65:186-202. doi:10.1016/j.watres.2014.07.025 (Elsevier Ltd)

Medlin L, Elwood HJ, Stickl S, Sogin ML (1988) The characterization of enzymatically amplified eukaryotic 16S-like rRNAcoding regions. Gene 71(2):491-499. doi:10.1016/0378-1119(88)90066-2 PO BOX 211, 1000 AE AMSTERDAM, NETHERLANDS (ELSEVIER SCIENCE BV)

Mendoza JL, Granados MR, de Godos I, Acién FG, Molina E, Heaven S, Banks CJ (2013) Oxygen transfer and evolution in microalgal culture in open raceways. Biores Technol 137:188-195. doi:10.1016/j.biortech.2013.03.127 (Elsevier Ltd)

Mutanda T, Ramesh D, Karthikeyan S, Kumari S, Anandraj A, Bux F (2011) Bioprospecting for hyper-lipid producing microalgal strains for sustainable biofuel production. Biores Technol 102(1):57-70. doi:10.1016/j.biortech.2010.06.077 (Elsevier Ltd)

Odlare M, Nehrenheim E, Ribé V, Thorin E, Gavare M, Grube M (2011) Cultivation of algae with indigenous species-Potentials for regional biofuel production. Appl Energy 88(10):3280-3285. doi:10.1016/j.apenergy.2011.01.006

Peña-Vázquez E, Pérez-Conde C, Costas E, Moreno-Bondi MC (2010) Development of a microalgal PAM test method for Cu(II) in waters: comparison of using spectrofluorometry. Ecotoxicol 19(6):1059-1065. doi:10.1007/s10646-010-0487-y 
Rabinowitch EI (1945) Photosynthesis and related processes. Interscience Publishers inc, New York. doi:bhl.title.5714

Ralph P, Gademann R (2005) Rapid light curves: a powerful tool to assess photosynthetic activity. Aquat Bot 82(3):222-237. doi:10.1016/j.aquabot.2005.02.006

Rawat I, Ranjith Kumar R, Mutanda T, Bux F (2013) Biodiesel from microalgae: a critical evaluation from laboratory to large scale production. Appl Energy 103:444-467. doi:10.1016/j.apenergy.2012.10.004

Salama E-S, Kim H-C, RaI Abou-Shanab, Ji M-K, Oh Y-K, Kim S-H, Jeon B-H (2013) Biomass, lipid content, and fatty acid composition of freshwater Chlamydomonas mexicana and Scenedesmus obliquus grown under salt stress. Bioprocess Biosyst Eng 36(6):827-833. doi:10.1007/s00449-013-0919-1

Schmitt-Jansen M, Altenburger R (2008) Community-level microalgal toxicity assessment by multiwavelength-excitation PAM fluorometry. Aquat Toxicol 86(1):49-58. doi:10.1016/j.aquatox.2007.10.001

Schreiber U, Klughammer C (2013) Wavelength-dependent photodamage to Chlorella investigated with a new type of multi-color PAM chlorophyll fluorometer. Photosynth Res 114(3):165-177. doi:10.1007/s11120-013-9801-x

Shiraiwa Y, Goyal A, Tolbert NE (1993) Alkalization of the medium by unicellular green algae during uptake of dissolved inorganic carbon. Plant Cell Physiol 34(5):649-657

Talbot P, Lencki MPGRW, Noiie J DE (1990) Absorption of $\mathrm{CO}_{2}$ in algal mass culture systems: a different characterization approach. Biotech Bioeng 37(9):834-842. doi:10.1002/bit.260370907

Tillmann U (2004) Interactions between planktonic microalgae and protozoan grazers. J Eukaryot Microbiol 51(2):156-168

Vonshak A, Laorawat S, Bunnag B, Tanticharoen M (2013) The effect of light availability on the photosynthetic activity and productivity of outdoor cultures of Arthrospira platensis (Spirulina). J Appl Phycol. doi:10.1007/s10811-013-0133-1

Wagener K (1983) Mass cultures of marine algae for energy farming in coastal deserts. -. Int J Biometeorol 27(3):227-233. doi:10.1007/BF02184238

Weissman JC, Tillet DM, Goebel RP (1989) Design and operation of an outdoor microalgae test facility final subcontract report design and operation of an facility, vol 1. Solar Energy Research Institute, Golden Colorado, pp 1-68

Winckelmann D, Bleeke F, Bergmann P, Klöck G (2014) Growth of cyanobacterium aponinum influenced by increasing salt concentrations and temperature. Biotech. doi:10.1007/s13205-014-0224-y

Xin L, Hu H, Ke G, Sun Y (2010) Effects of different nitrogen and phosphorus concentrations on the growth, nutrient uptake, and lipid accumulation of a freshwater microalga Scenedesmus sp. Biores Technol 101(14):5494-5500. doi:10.1016/j.biortech. 2010.02.016 